\title{
Cognitive, educational, and behavioural outcomes at 7 to 8 years in a national very low birthweight cohort
}

\author{
L John Horwood, Nina Mogridge, Brian A Darlow
}

\begin{abstract}
Aims-To examine cognitive, behavioural, and educational outcomes in middle childhood among a birth cohort of very low birthweight children.

Methods-Two hundred and ninety eight survivors from a national birth cohort of 413 New Zealand very low birthweight (VLBW) children born in 1986 were assessed at 7 to 8 years of age on measures of behaviour, cognitive ability, school performance and the need for special education. These outcomes were compared with the same measures in a general population sample of over 1000 children studied at a similar age.

Results-The VLBW children had significantly higher rates of problems and poorer levels of functioning across all outcome measures than the general child sample. These differences persisted even after control for variability in social, family, and other characteristics of the two samples and for the degree of sensorineural disability. There was evidence of a gradient of risk with birthweight, with extremely low birthweight children having generally higher rates of problems and difficulties than other VLBW children after covariate control.
\end{abstract}

Conclusions-The findings are consistent with a growing body of research evidence which suggests that premature and VLBW infants are at increased risk of longer term morbidity and functional impairment in middle childhood.

(Arch Dis Child Fetal Neonatal Ed 1998;79:F12-F20)

Keywords: very low birthweight; school achievement; cognitive ability; special education; behaviour problems

Christchurch Health and Development Study,

Christchurch School of

Medicine,

PO Box 4345,

Christchurch, New

Zealand

L J Horwood

Depatment of

Paediatrics,

Christchurch School of
Medicine,

N Mogridge

B A Darlow

Correspondence to:

Dr John Horwood.

Email:

Jhorwood@chmeds.ac.nz

Accepted 11 December 1997 weight controls, these children show consistently higher levels of problems and poorer functioning over a wide range of outcomes. In particular, VLBW infants tend to have higher levels of behavioural problemsspecifically, increased attention deficit and hyperactivity ${ }^{1-12}$; poorer performance on tests of cognitive ability ${ }^{212-19}$ and academic achievement $^{2361112141518-21}$; higher levels of learning problems; increased likelihood of need for special education or grade retention ${ }^{4}{ }^{13} 15192022$; poorer language and social skills ${ }^{2-4}{ }^{12}$; and poorer psychomotor skills. ${ }^{236141523}$ These findings have been obtained using a wide variety of measurement techniques and measurement instruments, and have been replicated using observations from a variety of sources, including parents, teachers, clinicians and standardised testing. Furthermore, several studies have suggested evidence of an inverse relation between birthweight and outcome risk, with the smallest infants having the greatest risk of later adverse outcomes, and normal birthweight infants the lowest risk. ${ }^{35} 61620$

There is a growing consensus about the long term outcomes for VLBW and extremely low birthweight (ELBW) children, but much of the research evidence comes from studies that are subject to potential selection biases. ${ }^{24-26}$ These biases arise from the highly heterogeneous nature of the samples studied. Factors contributing to this heterogeneity include: the frequent use of unit or hospital based samples; small sample size; high drop out rates; the variable application of exclusion criteria for assessment; the practice of combining births across a range of years to obtain sufficient sample numbers; and variable choice of cutoff points on the birthweight distribution. Among the smaller number of regional cohort or population based studies reported, the size and nature of the samples studied have varied considerably. To date there have been only a few studies on school aged outcomes for a comparatively large cohort of VLBW children with high rates of follow up that have compared these with outcomes for an equivalent control sample of normal birthweight children. ${ }^{1251415} 22$

This study therefore reports on the level of cognitive and behavioural functioning and educational achievement among a national cohort of New Zealand VLBW infants studied at the age of 7-8 years. The aims of the study were: (i) to document the overall levels of functioning and achievement for this cohort and, specifically, to examine differences in functioning between those children who were $<1000 \mathrm{~g}$ 
at birth and those weighing 1000-1499 $\mathrm{g}$ at birth; (ii) to compare the levels of cognitive, academic, and behavioural functioning in this cohort with a general population sample of children studied at a similar age; (iii) to determine the extent to which differences in levels of functioning between VLBW and other children could be explained by pre-existing differences between the cohorts, in terms of a range of measures of social and family background, perinatal, and other factors.

\section{Methods}

The data reported here were gathered in separate studies of two birth cohorts of children. These studies were conducted at different times but shared several features in common including: very similar data collection methods; supervision of data collection by the same research worker $(\mathrm{LJH})$; some overlap of data collection staff; and use of identical measurements for a range of childhood outcomes. This analysis is limited to the set of outcomes which were measured in both studies.

VLBW COHORT

The VLBW sample comprised all live born infants weighing less than $1500 \mathrm{~g}$ who were admitted to neonatal units throughout New Zealand in 1986 and who survived to follow up: 413 live born infants, of whom 338 $(81.8 \%)$ survived to hospital discharge. A further 12 children died before the age of 7 years. Of the surviving children at age 7-8 years, $17(5.2 \%$ of survivors $)$ were living outside New Zealand; the families of seven children $(2.1 \%$ of survivors $)$ declined to participate, and four children $(1.2 \%$ of survivors) could not be traced. The remaining 298 children $(96.4 \%$ of surviving children resident in New Zealand; $91.4 \%$ of all survivors) were assessed at follow up. The mean (SD) age at assessment was 91 (5) months.

Of the 298 children assessed, 77 were $<1000$ $\mathrm{g}$ at birth, and the remaining 221 weighed between 1000-1499 g. The mean (SD) birthweight for those $<1000 \mathrm{~g}$ was 823 (114) g, with the smallest child weighing $510 \mathrm{~g}$; the mean (SD) gestation was 27.1 (1.9) weeks, with a range of 24-34 weeks. For those weighing 1000-1499 g, the mean (SD) birthweight was 1267 (147) $\mathrm{g}$ and the mean (SD) gestation was 30.0 (2.2) weeks, with a range of 26-36 weeks.

The assessment for each child included: a parental interview covering a range of aspects of child development including physical disabilities, health history and medical contacts, schooling and educational problems, behavioural problems, and general family background; a detailed visual assessment of the child; and administration of the Wechsler Intelligence Scale for Children (WISC-R). ${ }^{27}$ Assessments were conducted by a team of six home visitors specially recruited and trained for the project. After the home assessment, teacher reports of the child's behaviour, academic achievement, and problems at school were obtained by postal questionnaire. Medical and other records were also obtained for children with identified physical, educational, and other disabilities. A detailed description of the sample and methodology of the follow up study has been given elsewhere. ${ }^{28}$ All information was gathered only after signed and informed consent from the child's parents or guardians had been obtained.

\section{CHRISTCHURCH HEALTH AND DEVELOPMENT} STUDY COHORT

For comparative purposes, the cohort of children studied in the Christchurch Health and Development Study ${ }^{29}{ }^{30}$ was used as a control series. In this study a birth cohort of 1265 children born in the Christchurch (New Zealand) urban region during four months in mid 1977 was studied at birth, 4 months, 1 year and at annual intervals to the age of 16 years, using a combination of methods including parental interview, direct assessment and interview of the child, teacher report, and information from medical and other records. At all stages of the study, the collection of information was conditional on obtaining signed and informed parental consent. The mean (SD) birthweight for the CHDS cohort was 3360 (534) g, and the mean (SD) gestation was 39.6 (1.6) weeks. Only five children in the CHDS were $<1500 \mathrm{~g}$ at birth, and none was less than 28 weeks of gestation.

Outcome comparisons are based on the eight year follow up of the CHDS cohort. At this age information was obtained from both parental interview and teacher report concerning various aspects of the child's behaviour and school performance over the period from 7-8 years. The children were also tested by the WISC-R. A total of 1092 of the original cohort of 1265 children were assessed at the 8 year follow up. Reasons for loss to follow up included emigration from New Zealand (91 families), death (15 children), and refusal to participate in the research (67 families). The final sample thus represented $94.2 \%$ of the cohort who were still alive and resident in New Zealand at the age of 8 . Most (95\%) of the sample were assessed within a month of their eighth birthday.

OUTCOME MEASURES

A series of measures of child behaviour, cognitive ability, and school achievement were available from the databases of the two studies. These measures were obtained using identical methods across the two studies.

\section{Measures of behaviour}

Parental ratings of child behaviour were obtained using a combination of the parental forms of the Rutter ${ }^{31}$ and Conners ${ }^{32}$ child behaviour questionnaires. Teacher ratings were obtained using by combining the teacher versions of the Rutter ${ }^{31}$ and Conners ${ }^{33}$ questionnaires. Scale scores were derived for the extent of behavioural problems and difficulties reported by both parents and teachers in each of three general dimensions of child behaviour: Attention deficit hyperactivity - the extent to which the child was reported to display inattentive, distractible, impulsive or hyperactive behaviours; 
Conduct problems - the extent to which the child was reported to display symptoms of aggressive, destructive, oppositional and similar behaviours;

Anxiety/withdrawal-the extent to which the child was reported to display shy, anxious, or withdrawn behaviours.

These three general dimensions of behaviour were used in previous studies of the CHDS cohort, ${ }^{34} 35$ and represent distinct, unidimensional measures of childhood behavioural variability. The reliabilities of the behaviour ratings, assessed using coefficient $\alpha$, ranged from 0.82 to 0.91 for measures of attention deficit/hyperactivity, from 0.84 to 0.93 for measures of conduct problems, and from 0.64 to 0.81 for measures of anxiety/withdrawal across the two samples.

To simplify data presentation, the parent and teacher scores were combined for each child to provide a global measure of the extent of behavioural variability in each of the three general behaviour domains. Cutoff points were then placed on these scores to define categorical measures representing the risk of more extreme problem behaviours and difficulties in each area. A child was classified as showing behaviour problems on a given behaviour domain if the child's score placed him/her above the 90th percentile on the joint distribution of the measure across the combined VLBW and CHDS cohorts.

The decision to use a categorical representation of the behaviour data was made primarily to maintain consistency with the other outcome measures examined. However, it should be noted that preliminary analyses of these data conducted on the continuously scored measures of parent and teacher ratings produced essentially identical conclusions as analyses based on categorical outcome criteria. The results also withstood the choice of cutoff point used to define problem behaviour criteria.

\section{Cognitive ability}

The WISC-R was used for both cohorts, ${ }^{27}$ focusing only on the full scale IQ score. The reliability of the WISC-R, as assessed by split half methods, was 0.93 for the CHDS cohort and 0.92 for the VLBW cohort. For a small number of children in the VLBW cohort $(5.8 \%$ of the sample) it was not possible to obtain a reliable assessment of IQ using the WISC-R, because of associated sensorineural problems or disabilities. However, using information available from other sources (medical records, reports of psychological assessments), it was clear that most of these children had severely impaired cognitive functioning.

For the purposes of the present analysis, the available WISC-R assessment information was used to define a binary measure of cognitive impairment. To be classified as having a cognitive impairment, the child had to meet one of the following criteria: either (a) the child's measured total IQ score was more than one standard deviation below the expected mean (total IQ < 85); or (b) the child was known on the basis of other available assessment information to be intellectually impaired.

\section{Teacher ratings of school performance}

Teachers were asked to rate the child's general level of performance in relation to their peers in each of five curriculum areas: reading; written expression; mathematics; spelling; and physical education. Ratings were made on a five point scale ranging from 1 (very good) to 5 (very poor). For the purposes of the present analysis, these ratings were classified into binary variables representing whether the teacher rated the child's performance as below average (poor or very poor) in relation to other children of the same age.

Special education

In addition to the overall assessment of school performance, detailed information was obtained on the extent of special education received by the child including: enrolment in a special school or special needs class/unit; the use of specialist services including speech/ language therapy, specialist teachers of the blind or deaf, Education Service psychologists, and related specialists; the use of teacher aides or other forms of remedial or special education funded by the Ministry of Education. This information was combined to form two binary measures of special education assistance: (a) whether the child was enrolled in a special school, class or unit; (b) whether the child received any form of Ministry of Education funded special education in the school setting.

\section{CONTROL VARIABLES}

To control for between cohort variability in pre-existing circumstances, a range of measures relating to family background, perinatal, and other factors were selected from the databases of the two studies. These measures were chosen on the basis that (a) they were measured in common across the two studies and (b) they were likely, given the available evidence from other studies, to be correlated with VLBW status, and/or predictive of the outcome measures studied. The measures chosen were as follows:

Measures of family sociodemographic background - maternal age at the child's birth; maternal education (no formal educational qualifications, secondary qualifications, tertiary qualifications); family type (single parent family, two parent family); child ethnicity (Maori/Pacific Island, other); maternal smoking during pregnancy (yes, no); duration of any breastfeeding (months);

Perinatal factors - gender, multiple birth, maternal parity, non-spontaneous delivery (forceps/ breech/caesarean section);

School related factors - grade level.

Table 1 shows a comparison of the covariate measures across the two cohorts. The VLBW cohort seems to reflect a mix of characteristics. On the one hand, the parents of the VLBW children were of higher parity $(p<0.01)$ and better educated $(p<0.05)$ than the mothers of the CHDS cohort. On the other hand, VLBW families contained significantly higher 
Table 1 Comparison of VLBW and CHDS cohorts on social, perinatal, and school related factors

\begin{tabular}{llll}
\hline Measure & $\begin{array}{l}\text { VLBW cohort } \\
(n=298)\end{array}$ & $\begin{array}{l}\text { CHDS cohort } \\
(n=1092)\end{array}$ & $p$ Value \\
\hline $\begin{array}{l}\text { Sociodemographic factors: } \\
\text { Mean age of mother at birth of child (years) }\end{array}$ & 25.8 & 25.8 & $>.80$ \\
$\quad$ Mother had no formal educational & $39.9 \%$ & $47.2 \%$ & $<.05$ \\
$\quad$ qualifications & $32.9 \%$ & $14.4 \%$ & $<.001$ \\
Child of Maori/Pacific Island ethnicity & $21.2 \%$ & $12.3 \%$ & $<.001$ \\
$\quad$ Single parent family & $33.9 \%$ & $34.2 \%$ & $>.80$ \\
Mother smoked during pregnancy & $72.5 \%$ & $70.5 \%$ & $>.50$ \\
Child fed breast milk ((1 month) & 3.9 & 4.0 & $>.60$ \\
$\quad$ Mean duration of breastfeeding (months) & & & $>.40$ \\
Perinatal factors: & $48.3 \%$ & $51.0 \%$ & $<.0001$ \\
$\quad$ Male & $24.2 \%$ & $2.1 \%$ & $<.0001$ \\
Multiple birth & $68.1 \%$ & $17.4 \%$ & $<.01$ \\
Non-spontaneous delivery & 2.3 & 2.0 & $<.05$ \\
$\quad$ Mean maternal parity & & & \\
School factors: & $17.7 \%$ & $24.2 \%$ & \\
$\quad$ Child in third year of schooling & & &
\end{tabular}

$(p<0.001)$ proportions of children of Maori or Pacific Island ethnicity and children living in single parent families. There were significantly higher $(p<0.0001)$ rates of multiple birth and non-spontaneous delivery in the VLBW cohort. Fewer children in the VLBW cohort were in their third year of schooling $(p<0.05)$, reflecting the fact that the VLBW cohort were assessed at a slightly younger age on average than children in the CHDS cohort. Rates of parental smoking and breastfeeding seemed to be similar across the two cohorts, as did the gender balance of subjects.

STATISTICAL ANALYSIS

Tests of the significance of bivariate associations between cohort membership and other measures were derived using $t$ tests for independent samples for mean comparisons, and $\chi^{2}$ tests of independence for comparisons of proportions. Statistical control for confounding variables was achieved using multiple logistic regression methods ${ }^{36}$ in which the log odds of each outcome measure were regressed on a series of design variables defining cohort membership and the significant covariates. Significant covariates were identified using methods of both forward and backward variable elimination, to identify the best fitting model for each outcome. In addition to the covariate measures listed above, to control for between cohort variability in the timing of assessments, the child's age in months at assessment was included in all regression equations. Adjusted risk distributions for each outcome were computed from the logistic model parameters using the method described by Lee. ${ }^{37}$ Odds ratio estimates and corresponding confidence intervals were also derived using the fitted model parameters.

\section{Results}

Table 2 shows comparisons of the rates of behavioural problems, cognitive impairment, poor school achievement and special education between the VLBW and CHDS cohorts. The VLBW cohort was further subdivided by birthweight to compare outcomes between ELBW and other VLBW children.

A substantial minority of children in the VLBW cohort were experiencing problems or difficulties across all domains of functioning: about $20 \%$ met criteria for individual behaviour problems; just under a quarter had WISC-R IQ scores which placed them more than one standard deviation below the expected mean; between $25-40 \%$ were performing poorly in each area of the curriculum; and just under a quarter were receiving some form of special education. However, there was little evidence to suggest substantial differences in overall outcome risks between children who weighed $<1000 \mathrm{~g}$ at birth and those who weighed 1000-1499 g. Outcome risks tended to be higher for the ELBW group, but this was not invariably the case and, in general, rates of problems and difficulties were very similar between the two groups.

Compared with the CHDS cohort, there were clear and highly significant $(p<0.0001)$ tendencies for levels of functioning to be poorer among children in the VLBW cohort across all areas of functioning: the odds ratios between outcomes and group status ranged from 2.1 to 4.4 for measures of behaviour, from 2.1 to 2.4 for cognitive impairment, from 1.7 to 4.9 for measures of school achievement, and from 2.9 to 6.3 for measures of special education.

To provide an approximate measure of the extent of impairment across multiple domains, an impairment score was constructed for each child as follows: for each of the four general domains of functioning examined in table 2 (behaviour problems, cognitive impairment, school performance, special needs), the child

Table 2 Rates (\%) of problem behaviour, cognitive impairment, school achievement, and special education assistance in VLBW and CHDS cohorts

\begin{tabular}{|c|c|c|c|c|c|c|}
\hline \multirow[b]{2}{*}{ Measure } & \multicolumn{2}{|c|}{$V L B W$ cohort } & \multirow{2}{*}{$\begin{array}{l}\text { CHDS cohort } \\
(n=1092)\end{array}$} & \multirow[b]{2}{*}{$p$ Value } & \multicolumn{2}{|l|}{ Odds ratio $(95 \%$ CI) } \\
\hline & $\begin{array}{l}<1000 g \\
(n=77)\end{array}$ & $\begin{array}{l}1000- \\
1499 \mathrm{~g} \\
(n=221)\end{array}$ & & & $\begin{array}{l}V L B W(<1000 \mathrm{~g}) \\
\text { vs } C H D S\end{array}$ & $\begin{array}{l}V L B W(1000-1499 \mathrm{~g}) \\
\text { vs } C H D S\end{array}$ \\
\hline \multicolumn{7}{|l|}{ Behaviour problems: } \\
\hline Inattention/hyperactivity & 21.3 & 22.1 & 7.4 & $<.0001$ & $3.4(1.9,6.2)$ & $3.5(2.4,5.3)$ \\
\hline Conduct problems & 12.0 & 18.0 & 8.1 & $<.0001$ & $2.1(0.7,4.3)$ & $2.5(1.6,3.8)$ \\
\hline Anxiety/withdrawal & 25.3 & 17.9 & 7.1 & $<.0001$ & $4.4(2.5,7.8)$ & $2.9(1.9,4.3)$ \\
\hline \multicolumn{7}{|l|}{ Cognitive impairment: } \\
\hline WISC-R Total IQ <85 & 24.0 & 21.2 & 11.5 & $<.0001$ & $2.4(1.4,4.3)$ & $2.1(1.4,3.1)$ \\
\hline \multicolumn{7}{|l|}{ Below average school performance } \\
\hline Reading & 23.9 & 29.3 & 15.6 & $<.0001$ & $1.7(1.0,3.0)$ & $2.2(1.6,3.1)$ \\
\hline Written expression & 37.1 & 37.4 & 20.3 & $<.0001$ & $2.3(1.4,3.9)$ & $2.3(1.7,3.2)$ \\
\hline Spelling & 41.3 & 40.7 & 21.3 & $<.0001$ & $2.6(1.6,4.3)$ & $2.5(1.9,3.5)$ \\
\hline Mathematics & 37.5 & 37.0 & 15.9 & $<.0001$ & $3.2(1.9,5.2)$ & $3.1(2.2,4.3)$ \\
\hline Physical education & 32.9 & 24.3 & 9.2 & $<.0001$ & $4.9(2.8,8.3)$ & $3.2(2.2,4.6)$ \\
\hline \multicolumn{7}{|l|}{ Special education assistance } \\
\hline Enrolled in special school, class or unit & 6.5 & 5.9 & 1.1 & $<.0001$ & $6.3(2.1,18.2)$ & $5.6(2.5,12.5)$ \\
\hline Receiving any form of special education assistance & 26.7 & 22.9 & 9.4 & $<.0001$ & $3.5(2.0,6.1)$ & $2.9(2.0,4.2)$ \\
\hline
\end{tabular}


Table 3 Rates (\%) of problem behaviour, cognitive impairment, school achievement and special education assistance in $V L B W$ and $C H D S$ cohorts after adjustment for covariates

\begin{tabular}{|c|c|c|c|c|c|}
\hline \multirow[b]{2}{*}{ Measure } & \multicolumn{2}{|c|}{$V L B W$ cohort } & \multirow{2}{*}{$\begin{array}{l}\text { CHDS } \\
\text { cohort }\end{array}$} & \multirow[b]{2}{*}{$p$ Value } & \multirow{2}{*}{$\begin{array}{l}\text { Significan } \\
\text { covariates }\end{array}$} \\
\hline & $<1000 \mathrm{~g}$ & $1000 g-1499 g$ & & & \\
\hline \multicolumn{6}{|l|}{ Behaviour problems: } \\
\hline Inattention/hyperactivity & 27.0 & 23.8 & 7.0 & $<0.0001$ & $1,2,6-8$ \\
\hline Conduct problems & 14.2 & 18.6 & 8.0 & $<0.0001$ & $1-3,5,7$ \\
\hline Anxiety/withdrawal & 29.8 & 20.0 & 6.9 & $<0.0001$ & 8,9 \\
\hline \multicolumn{6}{|l|}{ Cognitive impairment: } \\
\hline WISC-R Total IQ $<85$ & 36.2 & 24.7 & 10.7 & $<0.0001$ & $2,5,6,8,9$ \\
\hline \multicolumn{6}{|l|}{ Below average school performance: } \\
\hline Reading & 31.0 & 31.8 & 15.2 & $<0.0001$ & $1-4,8,9$ \\
\hline Written expression & 40.7 & 36.5 & 20.4 & $<0.0001$ & $1-4,8$ \\
\hline Spelling & 45.9 & 40.8 & 21.1 & $<0.0001$ & $3,4,6,8$ \\
\hline Mathematics & 43.7 & 37.5 & 15.7 & $<0.0001$ & $1,2,8$ \\
\hline Physical education & 32.8 & 22.3 & 9.4 & $<0.0001$ & $1,5,8$ \\
\hline \multicolumn{6}{|l|}{ Special education assistance: } \\
\hline Enrolled in special school, class or unit & 8.7 & 6.5 & 1.1 & $<0.0001$ & 5,9 \\
\hline Receiving any form of special education assistance & 30.7 & 24.1 & 9.3 & $<0.0001$ & 1,2 \\
\hline
\end{tabular}

was classified as having an impairment if s/he met criteria for any outcome in that domain. A count was then derived of the number of areas (out of four) in which the child had an impairment. Overall, $71 \%$ of children in the VLBW cohort experienced problems or impairments in at least one of the four general domains of functioning examined in table $2,42 \%$ in two or more domains, and $19 \%$ in three or more. By comparison, the corresponding figures for the CHDS cohort were $42 \%, 16 \%$, and $7 \%$, respectively $(p<0.0001)$. These results further highlight the fact that the general density of problems and difficulties in the VLBW cohort was substantially greater than in the general child population sample.

CONTROL FOR CONFOUNDING COVARIATES To examine the possibility that the differences observed in table 2 could be explained by preexisting differences in social and other characteristics between the two cohorts, the data were reanalysed using multiple logistic regression methods to control for the social, perinatal, and school related factors (table 1). In these analyses the log odds of each outcome measure was regressed on variables describing cohort membership together with the covariate factors. The regression equations also included a variable describing the age of assessment for each child, to control for variability in the timing of assessment between studies.

Table 4 Odds ratios (95\% CIs) for VLBW cohort compared with CHDS cohort after adjustment for covariates

\begin{tabular}{lll}
\hline Measure & $\begin{array}{l}V L B W(<1000 \mathrm{~g}) \\
\text { vs CHDS }\end{array}$ & $\begin{array}{l}\text { VLBW } \\
(1000-1499 \mathrm{~g}) \\
\text { vs CHDS }\end{array}$ \\
\hline Behaviour problems: & $6.0(2.9,12.4)$ & $4.9(2.9,8.3)$ \\
$\quad$ Inattention/hyperactivity & $2.1(0.9,4.9)$ & $3.0(1.7,5.1)$ \\
$\quad$ Conduct problems & $5.9(3.1,11.3)$ & $3.4(2.0,5.8)$ \\
$\quad$ Anxiety/withdrawal & $6.3(3.1,12.9)$ & $3.2(1.9,5.3)$ \\
Cognitive impairment: & & $3.0(1.9,4.8)$ \\
$\quad$ WISC-R Total IQ <85 & $2.9(1.4,5.8)$ & $2.5(1.6,3.9)$ \\
Below average school performance: & $3.0(1.6,5.7)$ & $2.9(1.9,4.5)$ \\
$\quad$ Reading & $3.7(1.9,6.9)$ & $3.5(2.3,5.3)$ \\
$\quad$ Written expression & $4.6(2.5,8.4)$ & $2.9(1.7,4.8)$ \\
$\quad$ Spelling & $5.0(2.6,9.5)$ & $6.6(2.8,15.8)$ \\
$\quad$ Mathematics & $9.2(3.0,28.2)$ & $3.2(2.0,5.1)$ \\
$\quad$ Physical education & $4.6(2.4,8.6)$ & \\
$\quad$ Special education assistance: & & \\
$\quad$ Receiving any form of special education assistance &
\end{tabular}

The results of these analyses are summarised in tables 3 and 4 . Table 3 shows the adjusted rates of each outcome for each group after controlling for the covariate factors, together with an overall significance test of the between cohort differences derived from the logistic regression model, and a list of the covariates that were significant in each equation. The adjusted rates are the hypothetical rates for each outcome measure that would have been observed had the distribution of all covariate factors been identical across each group. ${ }^{37}$ Table 4 shows the adjusted odds ratios and corresponding 95\% confidence intervals derived from the fitted model parameters for each outcome. Separate estimates are given for comparisons of ELBW and other VLBW children with the CHDS cohort.

Table 4 shows that after adjustment for confounding covariates, all of the associations between group status and the outcome measures remained highly significant $(\mathrm{p}<0.0001)$. In fact, the effect of covariate control was to slightly increase the observed differentials between the VLBW and the CHDS cohorts across all outcome measures. This is most evident from comparison of the odds ratios in tables 2 and 4 . Before adjustment, the odds ratios for the ELBW group compared withthose of the CHDS cohort ranged from 1.7 to 6.3; after adjustment the range was 2.1 to 9.2. For the VLBW children weighing 1000-1499 g at birth, odds ratios before adjustment ranged from 2.1 to 5.6; after adjustment the range was 2.5 to 6.6 . The outcomes for which covariate adjustment seemed to produce the greatest increase in differential between the cohorts were the measures of cognitive impairment and inattention/hyperactivity.

Covariate adjustment also produced much clearer differentials between the ELBW and other VLBW children. For nine out of the 11 outcomes the adjusted rates in table 3 are clearly higher-in some cases substantially higher-among ELBW children compared with other VLBW children. For one of the remaining outcomes (reading performance), rates in the two groups were almost identical. For the other outcome (conduct problems), the 
adjusted rate for the ELBW group was lower than that for other VLBW children, but the adjusted results show less marked differences between these groups than the observed rates in table 2. Taken together, these results suggest that there is good evidence for a gradient correlation between birthweight and risks of impairment across all domains of functioning.

\section{ADDITIONAL ANALYSES}

The logistic regression analyses reported in tables 3 and 4 were extended to examine several other issues relating to the risk of adverse outcomes.

\section{Control for degree of sensorineural disability}

One possible explanation for the excess risk of adverse educational and behavioural outcomes among VLBW children is that a substantial minority of these children have some degree of detectable sensory or neurological impairment, and that were the degree of sensorineural impairment to be taken into account, any observable increase in the risk of these outcomes would be explained. To examine this possibility, the data were reanalysed to include a measure of the degree of sensorineural disability in the regression models for behavioural and educational outcomes. The degree of sensorineural disability was graded on a four point scale ranging from none to severe, ${ }^{28}$ defined using the criteria from the Victoria Infant Collaborative Study. ${ }^{38}$ The classification of disability on this scale involves an assessment of the degree of disability from cerebral palsy, blindness, deafness and intellectual impairment. This analysis showed that, even after adjusting for the degree of sensorineural disability, the VLBW children tended to have higher rates of behaviour problems, poorer functioning in all areas of school performance, and greater need for special education $(p<0.01)$. After this adjustment the odds ratios for these outcome measures in the ELBW group compared with the CHDS cohort, ranged from 1.7-5.9, and for VLBW children weighing 1000-1499 g, it ranged from 1.9-4.6. These odds ratios are somewhat smaller than those seen in table 4, suggesting that control for degree of sensorineural disability accounted for some of the differences in performance between VLBW and other children. Nevertheless, the results clearly suggest that even among VLBW children without observable neurological disability, there was a detectable increase in the risk of adverse educational and behavioural outcomes at 7-8 years of age.

\section{Chronological age vs corrected age}

In common with most other studies in this area, the results of our study were based on analyses involving chronological age at assessment. However, it has been argued that age adjusted for prematurity would provide a more appropriate basis for comparison, at least up to school age. ${ }^{24}{ }^{39}$ To examine this possibility, the data were reanalysed to include in the regression equations an estimate of age at assessment adjusted for prematurity. This analysis did not materially alter the conclusions drawn from the analyses already reported in tables 3 and 4, suggesting that issues relating to the choice of adjusted age vs chronological age are largely irrelevant by middle childhood.

\section{Gender differences}

The covariate adjusted results in table 3 show that for seven out of the 11 outcome measures, gender was a significant covariate. Boys had significantly higher rates of problems and poorer overall levels of functioning than girls when averaged over the two cohorts. But is there any evidence of gender differences in the gradient of risk across different outcomes? To examine this possibility a range of logistic models was fitted to the data to test for gender interactions in the associations between cohort membership and outcomes. The results of this analysis clearly showed that there was no association between gender and VLBW status across all outcomes, suggesting that the overall gradient of risk for boys was similar to that for girls. In other words, although boys had higher overall risks for some outcomes than girls, the relative risks of problems among VLBW boys, compared with boys in the general child sample, were similar to the relative risks for VLBW girls, compared with girls from the general child sample.

\section{Discussion}

The results of the study are consistent with an emerging body of evidence on the longer term consequences for children of VLBW. It is clear that a substantial number of children in this cohort of VLBW children were experiencing problems and impairments of functioning at the age of $7-8$ years: between $20-40 \%$ of these children were identified as exhibiting high levels of behavioural problems, cognitive impairment, poor school achievement, or requiring special education. In total, nearly three out of four children in the cohort had impaired functioning in at least one of the domains examined: over $40 \%$ were impaired in two or more domains.

Comparted with the general child population sample, VLBW children showed clear and consistent tendencies towards poorer levels of functioning across all domains examined. These differences persisted even after control for pre-existing differences in social, perinatal, and other characteristics of the two cohorts, and regardless of whether chronological age or age adjusted for prematurity was used as the criterion for measurement. Taken together, these results provide strong evidence to suggest that, as a group, VLBW children are at increased risk of behavioural problems, intellectual and educational difficulties, and have much greater need for special education than children in the general child population. This increased risk is reflected in a greater density of problems and difficulties among VLBW children, with substantially more of these children having impairments in multiple domains of functioning than in the general child population. These findings corroborate a growing body of research in this area. ${ }^{1-26}$ 
A question of interest to a number of researchers has been whether the observed excess risk of problems among VLBW children is limited to those with detectable neurological disabilities or whether there are more subtle deficits experienced even among those without obvious neurological damage. ${ }^{26}$ Typically, researchers have approached this question either by excluding from their samples those children with detectable sensorineural disabilities, or by conducting separate analyses on samples, excluding those with recognisable neurological impairment (usually defined as having an IQ score of <85). A few studies have used the alternative approach of introducing a measure such as IQ into regression analyses to control for the degree of neurological impairment in the sample. We used a similar approach in this study by including a measure of the extent of sensorineural disability in supplementary analyses. These analyses showed that even after control for potential confounding factors and the degree of detectable sensorineural disability, levels of school achievement were clearly lower and behavioural problems among the VLBW cohort were clearly higher compared with those of the general child population. Similar conclusions have been drawn from other studies, ${ }^{312} 181922$ suggesting that the increased risk of adverse long term educational and behavioural outcomes applies to VLBW children in general, and not simply to those with detectable disabilities.

These findings suggest that the longer term prognosis for VLBW children is not particularly promising. At the same time it is important not to interpret these results in a totally pessimistic light. The outcome measures used in the present study provide fairly gross measures of impairment and, to that extent, it would be expected that some degree of impairment would be relatively common in any child sample. It is true that most VLBW children exhibited impairments in some area of functioning, but it is also the case that similar impairments were common among the CHDS cohort. Although VLBW children had consistently poorer overall levels of functioning, nevertheless, most VLBW children were functioning within the normal range of variability across all measures of behaviour and educational achievement, suggesting that for a substantial proportion of these children, their VLBW status may have little practical importance on their subsequent development. This conclusion is supported by recent studies of health related quality of life among the Canadian cohort of ELBW children studied by Saigal and colleagues. ${ }^{15}{ }^{22}$ As teenagers these children reported greater morbidity and functional impairment than normal birthweight controls, but on self reported quality of life measures, the two groups were generally very similar. $^{4041}$

Of all the outcomes examined, enrolment in special education facilities was the outcome most strongly related to VLBW status: even after adjustment for covariates, VLBW children had odds of enrolment up to ninefold higher than children in the general child sample. This is supported by similar findings in other studies. ${ }^{5} 1920$ It seems likely that this substantial differential reflects the now well established observation that among extremely premature and VLBW children, a small minority experience a considerable degree of disability that can only be catered for within highly specialised educational settings. We have shown elsewhere that $9.7 \%$ of this VLBW cohort may be classified as having a moderate or severe sensorineural disability, ${ }^{28}$ and it is largely these children who were enrolled in special education facilities. At the same time, it is also possible that some component of this differential may be spurious and arise from a selection or labelling bias, in which children identified as VLBW are more likely to be monitored closely through childhood and thereby be granted greater access to specialist services. Apart from enrolment in special education facilities, the highest odds ratios were observed for the ELBW group on measures of cognitive impairment and inattention/hyperactivity. It is in these two areas that perhaps the most consistent findings have emerged in studies of other VLBW samples, which suggests that, as a group, VLBW children may be at particular risk of cognitive disability and problems of inattention and hyperactivity.

Consideration of the patterning of outcome risk with birthweight suggested evidence to support a gradient model of the relation between birthweight and levels of functioning: almost without exception, after covariate adjustment, ELBW children had higher rates of problems and difficulties than other VLBW children who in turn had higher rates than the general child sample. This pattern of results was repeated for outcomes across all domains of functioning examined. The gradient relation seemed to be similar for boys and girls, despite the fact that boys had higher risks of some outcomes than girls. This latter result is reassuring to the extent that, while it is well known that boys have higher risks of many adverse perinatal and childhood outcomes, VLBW boys, if they survive, do not seem to be at greater relative risk than VLBW girls in terms of overall levels of functioning in middle childhood. Compared with the general child population, the odds of poor cognitive, educational, or behavioural outcomes among VLBW children seem to be the same for both boys and girls.

A major strength of this study lies in the fact that it is one of only a very few population based cohort studies that have documented school aged outcomes for a relatively large sample of VLBW children. ${ }^{151415224243}$ The study is almost unique in that there are only two other true national cohort studies in existence: the Dutch follow up study of the cohort of VLBW and preterm children born in the Netherlands in $1983^{42}$; and the Scottish Low Birthweight Study of children born weighing $<1750 \mathrm{~g}$ in Scotland in $1984 .^{43}$ The Scottish study has yet to publish school aged follow up data, and both studies lack comparative data on an equivalent control population. Of the remaining population based studies, the present study probably has greatest similarity 
with the research being conducted by Saigal and colleagues ${ }^{15} 22$ on a regional cohort of ELBW Canadian children born between 1977 and 1981. In this study 143 ELBW children were compared with matched controls on school aged outcomes, and had poorer overall levels of functioning across a wide range of cognitive, educational, and other measures of functioning.

A potential weakness of the study, however, is in the selection of the CHDS cohort as a control sample. This cohort was born in 1977, some nine years earlier than the VLBW cohort, and this raises the possibility that any differences between the cohorts may have been obscured in some way as a result of across time changes in measurement processes or social or other conditions between 1977 and 1986 . While the use of historical controls may be questionable, some reassurance on this matter can be gained from the observation that the data collection processes used in the two studies were supervised by the same researcher $(\mathrm{LJH})$, using identical measurement instruments administered in essentially identical circumstances. In addition, there was some carryover of data collection personnel between the two studies, which helped to ensure consistency of measurement methods.

Furthermore, it seems likely that the only major changes in the period between the two studies were linked to the rapidly improving medical technology for the care of VLBW infants, which, if anything, would have improved the observed outcomes for the VLBW cohort while having no detectable impact on outcomes in the general child population. Finally, the evidence from other research on the longer term outcomes for VLBW children provides further reassurance that the differences shown here are not artefactual.

While there are clear differences in overall levels of functioning between VLBW and other children, in the wider context the results do not suggest that VLBW is a major contributor to variability in general patterns of child behaviour and school achievement in middle childhood. Typically, after adjustment for covariates, VLBW children had odds for most outcomes that were about 2-5 times greater than those for the CHDS cohort, suggesting an effect size in the small to moderate range. This finding, coupled with the fact that VLBW children constitute only a very small proportion of the general child population (currently around $1 \%$ of live births in New Zealand), suggests that, at best, the impact of VLBW in explaining the variability in childhood outcomes is likely to be very small. This is reflected in estimates of population attributable risk derived from the adjusted rates in table 3 . These estimates suggest that VLBW would probably account for between $1-6 \%$ of the overall prevalence of the outcomes examined.

In reviewing the evidence on longer term outcomes for VLBW and premature infants, several commentators have highlighted the lack of standardised assessment criteria in the field. ${ }^{24}{ }^{26}{ }^{44}$ With the possible exception of the WISC-R IQ test, the source, nature, and content of assessment tools used across studies varies considerably. This study adds yet further measures to this array. However, while the lack of standardised assessment criteria can be seen as a weakness, in some sense it is also a strength, to the extent that the convergence of findings from a range of studies using a variety of assessment tools, but all leading to generally similar conclusions, provides strong grounds for the assertion that premature and VLBW children are at greater risk of longer term functional morbidity.

Seen against this background, the results of this study are not surprising. They nevertheless serve as a further reminder that technological interventions used to enhance the survival and life chances of very small and premature infants also bring with them the associated cost of an increased risk of subsequent impaired functioning. It remains the challenge of neonatal medicine to determine the extent to which further improvements in medical technology can address, not only issues relating to the neonatal outcome for VLBW and premature infants, but also the wider issue of reduction in the risk of longer term morbidity among these children.

The Christchurch Health and Development Study was funded by grants from the Health Research Council of New Zealand, the National Child Health Research Foundation and the Canterbury Medical Research Foundation. The VLBW Follow-up Study was funded by a research grant from the Follow-up Study was funded by a resea

We thank Dr David Fergusson, Executive Director of the We thank Dr David Fergusson, Executive Director of the
Christchurch Health and Development Study for his advice and assistance in conducting this research. We are also very grateful to the research staff involved in data collection for the two studies, and to the many families, children, teachers and health professionals who took part in or contributed to these projects.

1 Pharoah POD, Stevenson CJ, Cooke RWI, Stevenson RC. Prevalence of behaviour disorders in low birthweight infants. Arch Dis Child 1994;70:271-4.

2 Hack M, Taylor HG, Klein N, Eiben R, Schatschneider C, Mercuri-Minich N. School-age outcomes in children with Mercuri-Minich N. School-age outcomes in children with
birthweights under 750g. N Engl f Med 1994;331:753-9.

3 Klebanov PK, Brooks-Gunn J, McCormick MC. Classroom behavior of very low birthweight elementary school children. Pediatrics 1994;94:700-8.

4 Schothorst PF, van England H. Long-term behavioural sequelae of prematurity. 7 Am Acad Child Adolesc Psychiatry 1996;35:175-83.

5 McCormick MC, Gortmaker SL, Sobol AM. Very low birthweight children: Behavior problems and school difficulty in a national sample. $\mathcal{F}$ Pediatr 1990;117:687-93.

6 McCormick MC, Workman-Daniels K, Brooks-Gunn J. The behavioural and emotional well-being of school-age children with different birthweights. Pediatrics 1996;97:1825.

7 Breslau N, Brown GG, DelDotto JE, et al. Psychiatric sequelae of low birthweight at six years of age. $\mathcal{F}$ Abnorm Child Psychol 1996;24:385-400.

8 Szatmari P, Saigal S, Rosenbaum P, Campbell P, King S. Psychiatric disorders at five years among children with birthweights less than 1000g: A regional perspective. Dev Med Child Neurol 1990;32:954-62.

9 Marlow N, Roberts L, Cooke R. Outcomes at 8 years for children with birthweights of $1250 \mathrm{~g}$ or less. Arch Dis Child 1993;68:286-90.

10 Sommerfelt K, Troland K, Ellertsen B, Markestad T. Behavioural problems in low-birthweight preschoolers. Dev Med Child Neurol 1996;38:927-40.

11 Sommerfelt K, Ellertsen B, Markestad T. Personality and behavior in eight-year-old, non-handicapped children with birthweight under 1500g. Acta Paediatr 1993;82:723-8.

12 Hack M, Breslau N, Aram D, Weissman B, Klein N, Borawski-Clark E. The effect of very low birthweight and social risk on neurocognitive abilities at school age. $\mathcal{f} \mathrm{Dev}$ Behav Pediatr 1992;13:412-20.

13 Halsey CL, Collin MF, Anderson CL. Extremely low-birthweight children and their peers: A comparison of school-age outcomes. Arch Pediatr Adolesc Med 1996;150:790-4.

14 Pharoah POD, Stevenson CJ, Cooke RWI, Stevenson RC. Clinical and subclinical deficits at 8 years in a geographically defined cohort of low birthweight infants. Arch Dis Child 1994;70: 264-70. 
15 Saigal S, Szatmari P, Rosenbaum P, Campbell D, King S. Cognitive abilities and school performance of extremely birthweight children and match children at age 8 years: A regional study. $\mathcal{F}$ Pediatr

16 Breslau N, DelDotto JE, Brown GG, et al. A gradient relationship between low birthweight and IQ at age 6 years. Arch Pediatr Adolesc Med 1994;148:377-83.

17 Rickards AL, Kitchen WH, Doyle LW, Ford GW, Kelly EA Callanan C. Cognition, school performance, and behavior in very low birthweight and normal birthweight children at 8 years of age: A longitudinal study. $\mathcal{F}$ Dev Behav Pediatrics 1993;14:363-8.

18 Klein NK, Hack M, Breslau N. Children who were very low birthweight: Development and academic achievement at nine years of age. $\mathcal{F}$ Dev Behav Pediatr 1989;10:32-7.

19 Ross G, Lipper EG, Auld PAM. Educational status and school-related abilities in very low birthweight premature school-related abilities in very low birth
children. Pediatrics 1991;88:1125-34.

20 Klebanov PK, Brooks-Gunn J, McCormick MC. School achievement and failure in very low birthweight children. $f$ achievement and failure in very low

21 O'Callaghan MJ, Burns YR, Gray PH, et al. School performance of ELBW children: A controlled study. Dev Med Child Neurol 1996;38:917-26.

22 Saigal S, Rosenbaum P, Szatmari P, Campbell D. Learning disabilities and school problems in a regional cohort of extremely low birthweight $(<1000 \mathrm{~g})$ children: A comparison with term controls. F Dev Behav Pediatr 1991;12:294300.

23 Powls A, Botting N, Cooke RWI, Marlow N. Motor impairment in children 12 to 13 years old with a birthweight of less than 1250g. Arch Dis Child 1995;72:F62-6.

24 Hack M, Klein N, Taylor HG. School-age outcomes of children of extremely low birthweight and gestational age. Semin Neonatal 1996;1:277-88.

25 Ornstein M, Ohlsson A, Edmonds J, Asztalos E. Neonatal follow-up of very low birthweight/extremely low birthfollow-up of very low birthweight/extremely low birthweight infants to school age:
diatr Scand 1991;80:741-8.

26 Breslau N. Psychiatric sequalae of low birthweight. Epidemiol Rev 1995;17:96-106.

27 Wechsler D. Wechsler Intelligence Scale for Children - Revised. New York: The Psychological Corporation, 1974

28 Darlow BA, Horwood LJ, Mogridge N, Clemett RS Prospective study of New Zealand very low birthweight infants: Outcome at 7-8 years. $\mathcal{F}$ Paediatr Child Health 1997;33:47-51.
29 Fergusson DM, Horwood LJ, Shannon FT, Lawton JM. The Christchurch Child Development Study: A review of epidemiological findings. Paediatr Perinatal Epidemiol 1989;3:278-301.

30 Fergusson DM, Horwood LJ, Shannon FT. Factors related to the age of attainment of nocturnal bladder control: An eight year longitudinal study. Pediatrics 1986;78:884-90.

31 Rutter M, Tizard J, Whitmore K. Education, Health and Behaviour. London: Longmans, 1970.

32 Conners CK. Symptom patterns in hyperkinetic, neurotic and normal children. Child Dev 1970;41:667-82.

33 Conners CK. A teacher rating scale for use in drug studies with children. Am F Psychiatry 1969;126:884-8.

34 Fergusson DM, Horwood LJ. The structure, stability and correlations of the trait components of conduct disorder, attention deficit and anxiety/withdrawal reports. $\mathcal{F}$ Child Psychol Psychiatry 1993;34:749-66.

35 Fergusson DM, Horwood LJ, Lynskey MT. The stability of disruptive childhood behaviors. $\mathcal{F}$ Abnorm Child Psychol 1995;23:379-96.

36 SAS Institute Inc. SAS User's Guide: Statistics. Version 5 Edition. Cary, NC: SAS Institute Inc, 1985.

37 Lee J. Covariance adjustment of rates based on the multiple logistic regression model. $\mathcal{F}$ Chron Dis 1981;34:415-26.

38 Victorian Infant Collaborative Study Group. Outcome to five years of age of children born at 24-26 weeks five years of age of children born at 24-26 weeks
gestational age in Victoria. Med 7 A Aust 1995;163:11-14.

39 Rickards AL, Kitchen WH, Doyle LW, Kelly EA. Correction of developmental and intelligence test scores for premature birth. Aust Paediatr f 1989;25:127-9.

40 Saigal S, Feeny D, Rosenbaum P, Furlong W, Burrows E, Stoskopf B. Self-perceived health status and health-related qualify of life of extremely low birthweight teenagers:

(t) controls. FAMenbaum PL, Burrows E. How preeny DH, Furlong quality of life: Comparison with controls. Pediatr Res 1995;37:271A

42 Hille ETM, Den Ouden AL, Bauer L, Van der Oudenrijn C, Brand R, Verloove-Vanhorick S. School performance at nine years of age in very premature and very low nine years of age in very premature and very low birthweight infants: Perinatal risk factors and

43 The Scottish Low Birthweight Study Group. The Scottish low birthweight study: II. Language, attainment, cognitive status and behavioural problems. Arch Dis Child 1992; 67: $682-6$. 